\title{
El lenguaje sígnico y los comienzos de la edad del juicio. Breve apunte sobre dos métodos de la semiótica moderna
}

\author{
Nélida Guadalupe Arqueros \\ UNNE

\section{Resumen} \\ En la reflexión se retoma el estudio de los signos que se desarrolla en la escuela de la \\ abadía jansenista de Port-Royal durante el siglo XVII, y las posteriores especulaciones sobre el \\ origen del lenguaje de Étinne B. de Condillac para analizar dos concepciones semióticas de la \\ modernidad y de cómo reflejan las modificaciones que comienzan a producirse en los nuevos \\ estratos epistemológicos de la época.
}

\section{Palabras clave \\ Lenguaje - Representación - Modernidad}

Nos proponemos indagar brevemente en las primeras especulaciones en torno de nociones semióticas iniciadas en Europa y en especial en Francia, en el siglo XVII contenidas y desarrolladas en las llamadas gramáticas generales. También rastrear a su vez el cambio en las concepciones del lenguaje de la temprana modernidad, donde el pensamiento mágico y representativo que aliaba las palabras con la naturaleza se va disolviendo en la necesidad de construir sistemas de medición y escala; más rigurosos en relación con los nuevos conocimientos y epistemes. ${ }^{36}$

Eran muchas las gramáticas generales que se escribian en ese momento, se destacan las de Bauzeé en 1767 y de Cordemoy en 1677. Todas ellas se proponían extraer de un conjunto de hechos fundamentales, principios comunes como modelos para todas las lenguas, aunque admitian formaciones excepcionales para los casos particulares que eran cada una de ellas. Las gramáticas generales tenian como función una explicación del idioma por medio del acto del espiritu que se expresa entendido como un lenguaje y en su principal especial y primigenia: juzgar; de aquí su relación con la lógica traducida al análisis de la proposición.

\section{El racionalismo}

Antoine Arnauld y Claude Lancelot eran dos linguistas de la abadía jansenista de PortRoyal que habían sido educados en las escuelas menores. En 1660 era una novedad redactar en francés un ensayo de filosofia del lenguaje al alcance del lector no latinista: pero esto se cumple con la edición de la Grammaire géneralé et raizonée. Entre todas las gramáticas se destaca ésta por su clara influencia cartesiana por un lado, producto de la educación de sus autores, y escolástica por otro. Se publica además 23 años después del Discurso del método, y la relación se manifiesta en la elección por parte de los autores del método analítico cartesiano. En la teoría

${ }^{36}$ Léase además como una reflexión luego de la lectura de algunos capitulos de Las palabras y las cosas de Michel Foucault. Cfr. FOUCAULT, Michel. Las palabras y las cosas, Siglo XXI, Madrid, 1998. 
desarrollada en Port-Royal el discurso corresponde a una idea compleja, y las oraciones se subdividen en frases consecutivas, que a su vez se subdividen en frases, y así sucesivamente, hasta llegar al nivel de la palabra. En muchos pasajes se explicita el método analítico propio del cartesianismo:

En el análisis se toman esas verdades conocidas en el examen particular de la cosa que se quiere conocer, y no se hace intervenir las máximas claras y evidentes más que a medida que se las va necesitando. En la síntesis se parten de las verdades más simples y generales, para pasar a las menos generales y complicadas, yendo así de lo que es claro y evidente a lo que necesita demostración. ${ }^{37}$

En el fragmento se ejemplifica la influencia del método racionalista en la obra. Por lo demás Descartes refiere al lenguaje en la $\mathrm{V}$ parte del Discurso a propósito de la ausencia de signos en los animales por carecer éstos de razón. Se deriva de la lectura del pasaje que la lengua implica el pensamiento y viceversa, pero no despliega más detalles de dicha correspondencia. ${ }^{38}$

La doctrina de Port Royal aparece en la actualidad como un cuerpo de definiciones coherentes que conforman un sistema de principios en torno de, a) el mecanismo de la significación, b) un estudio de la proposición y c) un análisis de las partes de la oración y sus propiedades. Que traduciendo resultan: una teoría del signo, una sintaxis del juicio y una gramática de los conceptos. La gramática (coinciden los autores de la época), es el arte de hablar y de explicar uno mismo sus pensamientos por medio de signos. Para hacer perdurables los sonidos y las voces los seres humanos inventaron los caracteres de la escritura que ya los griegos llamaban grámmata. Estos signos se clasifican en dos aspectos: en cuanto a su naturaleza física o realidad material, esto es sonidos y caracteres, por un lado; y la manera en que los humanos usan esos signos para significar el pensamiento esto es, la palabra como una seña de lo que transcurre en el espíritu. Nos centraremos en la segunda clasificación que ocupa la parte más importante de la Grammaire, y que se inicia de la siguiente manera:

Nos queda por examinar lo que tiene ella \{la palabra\} de espiritual, que constituye una de las mayores ventajas del hombre por encima de todos los demás animales, y que es una de las mayores pruebas de la razón. Es el uso que hacemos de ella para significar nuestros pensamientos, y esta invención maravillosa de componer con veinticinco o treinta sonidos esa infinita variedad de palabras, que no teniendo nada similar a lo que ocurre en nuestro espíritu, no dejan de descubrir a los demás todo el secreto de él,

\footnotetext{
${ }^{37}$ La logique ou l'art de penser IV, c Il, citado por DONZÉ, Roland, La gramática general y razonada de Port Royal. Contribución la historia de las ideas en Francia. EUDEBA, Buenos Aires, 1970.

${ }^{38}$ Cfr. DESCARTES, Rene. Discurso del método para conducir bien la propia razón y buscar la verdad en las ciencias. Orbis, Buenos Aires, 1983. Pág. 93-95.
} 
y de hacer entender a los que en él no pueden penetrar, todo lo que concebimos y todos los diversos movimientos de nuestra alma. ${ }^{39}$

Dos características se clarifican en la extracción precedente, por un lado que no existe un vínculo ni natural ni de ningún tipo, entre el sonido y el sentido al cual va ligado, no se muestra claro el de arbitrario, sin embargo consideramos que alude al mismo. Y por otro lado el carácter convencional, es decir los signos gramaticales fueron inventados e instituidos por los hombres por cuatro razones explicadas más tarde en el texto: expresión, comunicación, claridad y buen gusto. Es el momento indicado para precisar lo que el signo es. Cuando al mirar un objeto se lo considera en si mismo, en su propio ser, se obtiene la imagen de la cosa; ahora bien cuando centramos la atención en determinado objeto (primero) en tanto dicho objeto es representativo de otro (segundo), llegamos a la idea de signo. Este primer objeto es un signo cuya función es salirse y trascender a si mismo para provocar la imagen del segundo. De esta manera el signo tiene dos niveles de realidad para nuestros analíticos modernos: la palabra representativa y la idea representada por esta. Es evidente la influencia que tuvo la Grammaire en los linguistas muy posteriores como Ferdinand de Saussure, quien al caracterizar el signo recoge su legado en varios sentidos. Se destaca la visión centrada en el signo independientemente de los objetos y más cercano a la idea que ellos representan como también la arbitrariedad de las palabras, y por último la estructura diádica que lo compone, idea que más tarde Saussure completará ricamente para arribar a los conceptos de significante y significado. Para volver a 1660, el signo aquí se define desde estas tres variables:

- Certidumbre del enlace los divide en ciertos, la respiración seffala la vida, o probables, la palidez del embarazo.

- Forma de su enlace con lo que significa. Puede un signo pertenecer al conjunto de lo que designa, como los sintomas de una enfermedad, o separados de las cosas, como las figuras y simbolismos del mito recrean un acontecimiento ocurrido en un tiempo histórico.

- Origen del enlace los divide en naturales, como la imagen que se refleja en el espejo es producto de un objeto puesto ante él, o por convención, una palabra significa algo para un grupo de hombres.

Es el tercer ftem de la clasificación el que realiza plenamente la utilidad de todo el sistema de signos; ya que ilustra la necesidad humana de manejar imágenes y conceptos desde representaciones. Descartes coincidía con este pensamiento que lo ayudaba a distinguir la bestia del ser humano, y siglos más tarde lo retoman y complejizan las antropologías racionalistas al hablar de la capacidad simbólica de la cultura.

La definición de la palabra y la estructura del signo se completa con otra obra de la misma abadía que se publica en 1662 llamada Lógica o el arte de pensar, en ella se puntualiza: La idea de la cosa suscita la idea del sonido y la idea del sonido la de la cosa. ${ }^{40} \mathrm{La}$ distinción entre el sonido y la idea del sonido esta basada en la concepción de uno de los gramáticos que

${ }^{39}$ Grammaire géneralé et raizonée. Il c I p 16 citado por DONZÉ, Roland, La gramática general y razonada de Port Royal. Contribución la historia de las ideas en Francia. Ob. Cit. Pág. 38.

${ }^{40}$ La logique ou l'art de penser, I, c. I p 133 pasaje agregado en 1674. Citado por DONZÉ, Roland. Ob Cit. Pág. 41. 
redacta, Antoine Arnauld, sobre el mecanismo de la comunicación y la naturaleza del signo, es decir de la asociación de dos imágenes mentales una acústica y otra conceptual.

\section{El empirismo de Condillac}

Casi un siglo después de la publicación de la Lógica surge, también en Francia un filósofó iluminista llamado Étienne Bonnot de Condillac. Elegimos a este importante personaje intelectual por ser un feliz representante de su época y por la profundidad de su reflexión acerca del lenguaje entre otras cosas; que va en contra incluso de importantes empiristas contemporáneos suyos. ${ }^{41}$ En su obra Ensayo sobre el origen del conocimiento humano sacada a la luz en 1746, coincide con la concepción expuesta desde Port-Royal que afirma que no existe ningún pensamiento ni reflexión fuera o que anteceda al empleo de las palabras o signos. ${ }^{42}$ Esta afirmación se opone a Locke quien proclama que la idea es anterior a la palabra en la misma medida que el objeto es anterior a la idea. Otra coincidencia es que ambas doctrinas hacen buen uso del método analítico, incluso Condillac llega a postularlo como la forma de llegar a los signos del lenguaje. Distingue así tres clases de signos que difieren en sus naturalezas y en la profundidad significativa:

- Accidentales, que se vinculan casualmente a una causa y de esta manera evocan la idea.

- Naturales, que surgen espontáneamente y revelan ciertas necesidades, deseos, sentimientos o pasiones del sujeto, son gritos que la naturaleza ha establecido. ${ }^{43}$

- Convencionales que los seres humanos han conformado, guardando una relación arbitraria con las ideas.

El autor llama a las dos últimas clases lenguaje de la acción y lenguaje de palabras o verbal respectivamente. En la distinción se reproduce la antigua discusión griega, que da prueba el Cratilo platónico, entre el origen natural o convencional de las palabras. Veamos como la resuelve Condillac. Estos dos lenguajes son momentos diferentes de la evolución de la especie humana (su lectura diacrónica: se distancia del abordaje de Port-Royal). Es decir que en un primer momento todos los lenguajes fueron expresiones asistematicas de sentires internos. Todo es indiferenciado y confuso ya que no existe el propósito de comunicar ideas, ni la capacidad de analizar pensamientos. De la misma naturaleza van sacando las personas la necesidad de razonar y ordenar en un lenguaje sus primeras expresiones, de esta forma se llega a la formación del lenguaje sígnico. Poco a poco se va perfeccionando el análisis y desde él se forman las ideas y las convenciones como las designaciones propias de cada lengua y cultura. Queda de esta manera resuelto, el lenguaje es producto de la convención, pero la convención (y aquí Condillac recrea al Protágoras) es producto de la naturaleza que se niega y adquiere determinada forma para satisfacer las necesidades de los distintos grados de evolución del conocimiento humano. Otra cosa que se destaca es que a partir del aumento del conocimiento y

\footnotetext{
${ }^{41}$ Condillac es además un teórico adelantado al abogar por el otorgamiento de algunos derechos a las mujeres, en contra de otros pensadores contemporáneos. Cfr. AMORÓS PUENTE, Celia. Hacia una crítica de la razón patriarcal. Antrophos, Madrid, 1991.

${ }^{42}$ Cfr. CONDILLAC, Étienne Bonnot de. Ensayo sobre el origen del conocimiento humano, Madrid, 1922. Cap. IV.

${ }^{43}$ CONDILlaC, E. B. de. Ob. Cit. Pág. 132.
} 
grados más diversos del raciocinio se vuelve necesario un mejor uso del lenguaje y una precisión más compleja en la definición de los signos que lo integran. Como no se distinguen pensamiento y signo su complejización es paralela y se obtiene por medio del análisis. Nuevamente el método es de Descartes, aunque aplicado al perfeccionamiento de las lenguas, embrutecidas y contaminadas por metafisicos que las convierten en una jerga de retazos carentes de precisión conceptual.

Se han desplegado conjuntamente dos concepciones que abordan al lenguaje de diferente manera. Por un lado los lingüistas de Port-Royal realizan un análisis sincrónico de marcada tendencia racionalista y cartesiana. Desde el que se visualiza una teoria del signo que es un precedente importante. Se lee en ambos análisis una misma necesidad de precisar conceptos acerca del lenguaje. Desde el signo por un lado y desde el origen en el caso de Condillac. Resalta el hecho de ser filosofias y reflexiones profundas sobre el lenguaje, más que gramáticas explicativas de la totalidad de sus funcionamientos y rasgos generales. Demuestran y traducen ambas, un espíritu de la época, en la que el método científico comienza a estructurar y a imponerse en todos los saberes. Para manejarlo se demanda un lenguaje preciso y claridad en los conceptos. Las palabras se separan de las realidades para formar un universo aparte donde no hay lugar para la metáfora propia del pensamiento mágico. Estas gramáticas cumplen esa función, el signo es aquí una realidad privativa del ser humano y debe ser analizado como un instrumento propio y facilitador de las nuevas construcciones gnoseológicas que van llegando. 


\section{Bibliografía}

ARNAULD, A et LANCELOT, C. Gramaire generale et raisonnée, De L'imprimeire de Munier, Paris, 1803

CAPPELLETTI, Angel J. Introducción a Condillac, Biblioteca de textos filosóficos, Universidad de Zulia, Maracaibo, 1973

CHOMSKY, Noam. El lenguaje y el entendimiento, trad. Juan Ferrate y Salvador Oliva para los capítulos 4-6), Obras Maestras del pensamiento Contemporáneo, Planeta Agostini, Buenos Aires, 1992

CONDILLAC, Étinne Bonnot de. Ensayo sobre el origen del conocimiento humano, trad. E. Mazarriaga, Madrid, 1922

Buenos Aires, 1984

Lógica, trad. Josefina Analía Villa y José Gimeno, Orbis,

DE LA LINDE, Carmen. Algunas reflexiones sobre el lenguaje, Conicet, Ministerio de Cultura y Educación de la Nación, Buenos Aires, 1997

DESCARTES, Rene. Discurso del método para conducir bien la propia razón y buscar la verdad en las ciencias, trad. Antonio Rodríguez Huescar, Orbis, Buenos Aires, 1983

DONZÉ, Roland. La gramática general y razonada de Port- Royal. Contribución a la historia de las ideas gramaticales en Francia, trad. Marino Ayerra Redín, EUDEBA, Buenos Aires, 1970

FOUCAULT, Michel. Las palabras y las cosas, trad. Elsa Cecilia Frost, 26 ed., Siglo XXI, Madrid, 1998

LABORDA GIL, Xavier. La gramática de Port.Royal. Fuentes contenido e interpretación. Universidad de Barcelona, Barcelona, 1978.

TRÍAS, Eugenio. Metodología del Pensamiento Mágico, La Gaya Ciencia, Edhasa, Barcelona, 1970.

N. Guadalupe Arqueros. Licenciada en Filosofia (UNNE) y Especialista en Metodología de la Investigación (UNLa.) Profesora e investigadora de la Facultad de Humanidades de la UNNE. 